\title{
LA ESCAPE ROOMEDUCATIVA COMO PROPUESTA DE GAMIFICACIÓN PARA EL APRENDIZAJE DE LA HISTORIA EN EDUCACIÓN INFANTIL
}

\author{
Noemí Sanz Yepes \\ Universidad de Burgos
}

Almudena Alonso Centeno ${ }^{1}$

Universidad de Burgos

Recibido 08/11/2019 Aceptado 22/05/2020

El aprendizaje de la Historia frecuentemente se relaciona con etapas educativas diferentes de la Educación Infantil, dado el carácter estructural que tradicionalmente presenta la asignatura. Desde este punto de vista, considerarnos la gamificación como una estrategia didáctica de primer orden para introducir en el aula de Educación Infantil el concepto de temporalidad, cambio e Historia, tomando como punto de partida el diseño de una Escape Room Educativa. El empleo del elemento lúdico en el aprendizaje de la Historia permite conectar al alumnado con su entorno más próximo para relacionar distintos contenidos y competencias y lograr un conocimiento multidisciplinar.

History learning is often related to different educational stages of Early Childhood Education, because of the structural nature presents by the subject. From this point of view, we understand gamification as a first-order didactic strategy which introduce the concept of temporality, change and history, into the classroom of Early Childhood Education, taking the design of an Educational Escape Room as the starting point. The use of the ludic element in the learning of history allows students to connect with their closest environment in order to relate different contents and competences, so they could achieve multidisciplinary knowledge.

DOI

https://doi.org/10.15366/didacticas2020.22.001

\section{PALABRAs Clave}

Historia; Gamificación; Escape Room; Educación Infantil; Conocimiento del Entorno.

History; Gamification; Escape Room; Early Childhood Education; Knowledge of the Environment. 


\section{INTRODUCCIÓN}

El conocimiento del entorno más próximo, permite a los niños el desarrollo progresivo de habilidades cognitivas a lo largo de la etapa de Educación Infantil, lo que le permite la adecuación y construcción de su identidad a lo largo de su desarrollo intelectual (Blanco et al, 2018). De este modo, el alumnado no sólo se ve como parte del medio en el que vive, sino que además posibilita que sus necesidades sociales y educativas se vean cubiertas. Partiendo de este prisma y teniendo en cuenta que la comprensión de la dimensión espacial, la comprensión de la temporalidad y la historicidad, el desarrollo de habilidades comunicativas y la reflexión de forma crítica y propositiva, son habilidades cognitivas que permiten el desarrollo del aprendizaje de las Ciencias Sociales, hemos considerado incluirlas en el aula de Educación Infantil. Para ello, se parte de una propuesta focalizada en el elemento lúdico como punto de partida para el inicio de la construcción de conocimiento en Historia en particular y en Ciencias Sociales en general y el desarrollo de las competencias clave que establece el currículo de Educación Primaria y Secundaria (BOE núm. 25, de 29 de enero de 2015).

\section{LA HISTORIA COMO HERRAMIENTA DE APRENDIZAJE Y COMPREN- SIÓN DEL ENTORNO Y LA TEMPORALIDAD, EN LA ETAPA DE EDUCA- CIÓN INFANTIL}

Aunque de forma inconsciente, el niño forma parte de la sociedad y de este modo, también está en contacto con la Historia. La Historia se manifiesta como algo cotidiano en la vida de los más pequeños a través de los medios. Son frecuentes las series o películas infantiles de televisión que utilizan algún periodo histórico como recurso o ambientación. Por otro lado, los juegos en dispositivos digitales o diversos cuentos infantiles son presentados desde épocas pasadas. Desde este prisma, la relación que se mantiene en la infancia con el pasado, aunque este se presente de forma más o menos rigurosa, es estrecha y la predisposición a aceptarla como algo próximo también lo es. Por tanto, la posibilidad de introducir la Historia en el ámbito escolar no debería resultar algo novedoso, a pesar de su escasa presencia en el currículo de esta etapa (BOE de acuerdo con la Orden ECI/3960/2007, de 19 de diciembre).

En España, las Ciencias Sociales, y concretamente la Historia, forman parte específica del currículo de Educación Infantil de forma indirecta, reflejada por el estudio y observación del paso del tiempo, aunque se considere su inclusión en el área de Conocimiento del Entorno. Sin embargo, en países como Gran Bretaña, la Historia se incluye en las aulas de niños entre cinco y ocho años como enseñanza desde 1991, manteniéndose, con diversas modificaciones, en la actualidad (Miralles y Rivero, 2012). La Historia en edades tempranas no debe ser considerada remota o inverosímil, en los últimos años contamos con próximos ejemplos en Europa. 
La enseñanza de la Historia contribuye al desarrollo de las tres áreas del currículo (Conocimiento de sí mismo y autonomía personal, Conocimiento del entorno y Lenguajes: Comunicación y representación):

a) Contribuye a la construcción gradual de la propia identidad, aspecto relacionado con el área de Conocimiento de sí mismo y autonomía personal.

b) Ayuda a interpretar las huellas del pasado en el entorno y, por tanto, al conocimiento del entorno en sí mismo.

c) El trabajo con fuentes históricas y la elaboración de producciones propias del alumnado con información histórica implica el trabajo con diferentes formas de comunicación y de representación (Miralles y Rivero, 2012: p.82).

Podemos afirmar, por tanto, que las Ciencias Sociales y en consecuencia la Historia, no abarcan una única área del currículo de Educación Infantil, sino que es posible implementarla en las tres áreas existentes, lo que supone un punto de partida para apoyar la importancia de la enseñanza de la Historia en edades tempranas, dado que al abarcar las tres áreas de conocimiento favorece el desarrollo integral del niño.

Las investigaciones de Langford (1990), Downey y Levstik (1991), Torres Bravo (2001), Fuentes (2004) o Mariana y Rodríguez (2007), permiten confirmar que las dificultades que muestran los niños a la hora de aprender Historia o el tiempo histórico, están más vinculados a la manera en la que se lleva a cabo su enseñanza que a la complejidad del concepto, el desarrollo evolutivo o la edad del alumno (Cuenca, 2018). Esto plantea la necesidad de introducir cambios significativos que permitan la adecuación de determinados contenidos a la realidad del aula.

Así, el origen del concepto innovación surge en el contexto de la Revolución Industrial, aplicado a los cambios que se realizaban en las fábricas con la intención de conseguir una mejora en ellas. Por entonces, los resultados de éxito derivados del cambio eran escasos, lo que contribuyó a dificultar la aceptación como algo beneficioso del término innovación. Así, Godin (2012) planteó la necesidad de definir innovación sin esta restricción, de manera que pudiera ser aplicada a múltiples campos "Innovación es la modificación de las formas de hacer (o la aparición de nuevas formas de hacer) gracias a la invención o a la adopción de nuevos bienes, servicios o nuevas prácticas”.

En estos términos, y en relación a la innovación educativa, se puede concluir que la mayoría de las definiciones están dirigidas al uso de las Tecnologías de la Información y la Comunicación en el aula, como el principal factor innovador educativo. Aunque es cierto que el uso de las TIC en el aula es un método novedoso, su uso no debe ser considerado imprescindible. Por otro lado, Carbonell (2002) concibe una definición de innovación educativa más completa: 
"(Un) conjunto de ideas, procesos y estrategias, más o menos sistematizados, mediante los cuales se trata de introducir y provocar cambios en las prácticas educativas vigentes. [...] Su propósito es alterar la realidad vigente, modificando concepciones y actitudes, alterando métodos e intervenciones y mejorando o transformando, según los casos, los procesos de enseñanza y aprendizaje" (p. 3).

De igual modo, no sería adecuado centrarnos solo en el proceso, sopesar el papel que juega la persona que lo ejecuta es igual de relevante, como también lo es si la persona goza de los atributos necesarios para ponerlo en práctica (Ramírez y Valenzuela, 2017, p. 89). Así la noción de atributo complementaría las competencias del perfil de un innovador. Villa y Poblete (2007) estiman "La actitud, la intención y la disponibilidad son elementos preponderantes que sirven para encauzar el "saber hacer" de las competencias en fines específicos. Por ello, es importante que exista una interrelación de otros tipos de competencias instrumentales e interpersonales que jueguen un papel más integrador en la persona para ser perfilada como innovadora (Villa y Poblete, 2007).

Estas competencias serán adquiridas gracias a la práctica de las mismas, mejorando con el tiempo su eficacia a la hora de aplicarlas. Por otro lado, los atributos son características propias de la persona que, si no se poseen de manera innata, difícilmente se pueden adquirir. Michavilla $(2009$, p.4) incide también que la innovación educativa está estrechamente vinculada a la persona, en este caso, a la motivación, formación y evaluación del profesorado. Son los docentes los que en primera instancia deciden aceptar la innovación e implementarla adecuadamente. De la misma manera que, en ocasiones se encuentra que la innovación demanda cierta adaptación de los espacios lectivos para poder ejecutarla. De modo que, la innovación educativa pretende realizar cambios en los modelos didácticos actualmente vigentes en las aulas, Requiere de la voluntad y motivación del profesorado para llevarla a cabo y en ocasiones de la modificación o adaptación del espacio lectivo.

\section{LA GAMIFICACIÓN COMO ESTRATEGIA DIDÁCTICA EN EL APRENDIZAJE DE LA HIS- TORIA EN EDUCACIÓN INFANTIL}

A pesar de los diversos cambios sociales y culturales que han ido moldeando nuestra sociedad, el gusto de los niños por el juego se mantiene como una constante, si bien, los juegos cambian con el paso del tiempo, se mantiene la esencia que los caracteriza. En realidad, el juego es una actividad innata en el ser humano que permite tanto su comprensión del mundo como actuar en él. Además, para el niño el juego supone una forma de comunicarse, un lenguaje (Fernández y Serra, 2015). Los juegos, mejores o peores, más o menos didácticos han llamado la atención de la humanidad y han permitido, mediante su uso, interactuar con otras personas, incluso a través de una pantalla.

Por esta razón, en los últimos años se ha tratado de adaptar los juegos electrónicos a la vida real, en concreto a un contexto educativo. Este proceso consiste en extraer los elementos atractivos e identificativos de un juego, con la intención de trasladarlos a otra tarea 
dentro de un entorno de no juego (como puede ser el aula), para convertir dicha tarea en una dinámica lúdica y conseguir con ello una vinculación de los beneficiarios, con el fin de crear una experiencia, se llama gamificación, tal y como lo definen Marín y Hierro, s.f. Este proceso de gamificación nace de la importancia de aprender a través del juego primordialmente en edades tempranas.

\section{Escape Room educativa}

En el contexto de la gamificación, aparece un nuevo término: Escape Room. Traducida como "habitación de escape". Se trata de un juego dirigido, enfocado principalmente a los adultos, novedoso y en pleno auge en nuestra sociedad. Las Escape Rooms, también llamadas juegos de escape, son definidas como que implican una completa involucración basadas en el trabajo en equipo. En ellos los jugadores descubren pistas, resuelven acertijos, puzles y misiones pasando por una o varias estancias, con el fin de alcanzar un objetivo final con un límite de tiempo (Nicholson, 2015).

Teniendo en cuenta la novedad de este recurso, cabe esperar que su aplicación en el aula sea más novedosa todavía. Debido a esto, el término Escape Room educativa no se encuentra todavía suficientemente acotado. Así, proponemos la definición de Juego de Escape educativo como aquel que, utilizando la faceta lúdica de las Escape Rooms ordinarias, guía a los alumnos hacia el aprendizaje de los conocimientos correspondientes a su etapa, contando con el maestro como orientador durante todo el proceso. Están ambientadas y diseñadas en función del conocimiento que se quiera trabajar, aunque cuentan con la posibilidad de proyectarse como una herramienta multidisciplinar que finalmente conduce a una didáctica concreta.

Gracias a este enfoque multidisciplinar, no solo se centra en el aprendizaje de conceptos teóricos, sino que también ayuda a desarrollar en el alumno otras competencias como el trabajo en equipo, el diálogo, la resolución de problemas o el pensamiento crítico. El alumno es el protagonista de su aprendizaje mediante la experimentación y la indagación que permite este recurso, facilitando así la asimilación de conceptos. La duración de una Escape Room depende de la cantidad de actividades, enigmas, pruebas e interrogantes que la compongan, así como de la dificultad de las mismas. En definitiva, es un recurso didáctico que tiene como objetivo desarrollar las habilidades del alumno de la manera más completa posible, además de ayudarle en su proceso de aprendizaje facilitando la interiorización de conceptos a través de la experimentación propia.

Estas características permiten establecer que las Escape Room fomentan el trabajo en equipo, así como la resolución de conflictos, permiten desarrollar la experimentación del individuo y del grupo; por otro lado, la importancia del diálogo y la comunicación efectiva del grupo es evidente, donde los distintos enigmas planteados se resuelven de manera variada. 
La propuesta didáctica que presentamos a continuación parte de la implementación de las Escape Room en el aula, bajo la denominación de Escape Room Educativa. Para ello, como recurso didáctico proponemos el contexto de una Escape Room, tratando de aprovechar sobre todo su parte más dinámica. En la actualidad el término está asociado casi en exclusiva al entretenimiento, basado en el trabajo en equipo con el fin de superar diversas pruebas, enigmas, rompecabezas y otras incógnitas para lograr así un objetivo común, del que parte la actividad y le da nombre, escapar de la habitación en la que los participantes se encuentran "encerrados".

El dinamismo en el que se desarrolla la actividad, considerando que existe un tiempo limitado para llevarla a cabo, se plantea en conexión, como un todo, a los elementos didácticos presentados. En este caso, se trata de una Escape Room educativa dirigida a niños de Educación Infantil, entre 3 y 6 años, dentro del área de Conocimiento del Entorno, poniendo un especial énfasis en la didáctica de los contenidos propios de las Ciencias Sociales, desde un punto de vista integrador y multidisciplinar. Así, la Historia tendrá una especial relevancia, como punto de inicio del proyecto, en relación con otras disciplinas propias de las Ciencias Sociales, como la Geografía, la Etnografía, Antropología, Economía, etc. como parte indisoluble de un todo, motivando el conocimiento y la reflexión del entorno social y cultural próximo del alumnado.

El elemento didáctico del que parte este proyecto, que sirve como hilo conductor de la Escape Room educativa es la trashumancia y su implicación histórica. La elección de esta temática surge de la necesidad de integrar la Historia como parte fundamental en el proceso de enseñanza-aprendizaje del entorno social y cultural. Así, se plantea la Historia de la trashumancia como parte esencial de nuestra sociedad, contribuyendo a la creación tanto de instituciones, como elementos culturales y sociales que persisten en nuestros días. El papel de la trashumancia tuvo una especial relevancia a finales de la Edad Media, en relación con la institución de la Mesta. Sin embargo, este pasado ayudó a forjar el presente de esas comunidades. Así, en el presente Burgos se presenta como una de las ciudades de mayor importancia en el desarrollo de este oficio. La trashumancia no sólo es considerada como una parte ineludible de la Historia sino además una forma de vida presente aún en algunas comunidades de la actualidad. Se trata de una forma de vida que ha ido evolucionando a lo largo de los años, suponiendo el sustento de muchas familias hoy en día. Sin embargo, aunque esta práctica se mantenga más allá de nuestras fronteras, en nuestro país, la trashumancia es un oficio en franca decadencia. La práctica habitual de muchos ganaderos y pastores es el traslado de sus reses en camiones en lugar de recorrer las antiguas vías pecuarias que comunican el norte y el sur de la Península Ibérica. Por ello, supone un modo de trabajar el pasado desde el presente, permitiendo la comparación y reflexión, que lleve al alumnado a la creación de conocimiento. 


\section{PROYECTO "SOMOS PASTORES TRASHUMANTES"}

\section{Principales objetivos del proyecto}

Como objetivos de la propuesta planteamos lograr el aprendizaje de contenidos de Historia para obtener una importante base de información que les lleve a comprender el mundo en el que viven y el desarrollo del mismo. Para ello, la gamificación se plantea como una herramienta de gran utilidad. Aprovechando la motivación que proporciona una propuesta de carácter lúdico, se integrará un proceso de aprendizaje multidisciplinar, abarcando los aspectos fundamentales de las áreas planteadas curricularmente para Educación Infantil (Conocimiento de sí mismo y autonomía personal; Conocimiento del entorno y Lenguajes: comunicación y representación) (Real Decreto 1630/2006, de 29 de diciembre).

Por otro lado, y de manera prioritaria esta propuesta plantea acercar al alumnado al medio que le rodea, desde su propia experiencia y a través de diferentes actividades basadas en la investigación, la reflexión y fundamentada en el aprendizaje significativo. Así mismo, les permitirá una aproximación cultural a formas de vida distintas a la suya, que se mantienen en la actualidad, lo que les proporcionará la base para la comparación, reflexión y la creación de conocimiento, contribuyendo a la comprensión del funcionamiento su entorno más próximo. La consecución y ordenación de las actividades, están diseñadas de forma cronológica para que los alumnos entren en contacto con la percepción del paso del tiempo y logren comprenderlo desde la experiencia propia.

Por último, la realización de las actividades de manera conjunta, contribuirá a fomentar la relación entre iguales, la comunicación con los demás, la expresión y desarrollo de ideas propias, así como el respeto hacia las ideas de los demás, además de facilitar el aprendizaje significativo entre los alumnos, tomando como punto de partida la motivación del alumnado.

\section{Desarrollo del proyecto}

Las sesiones diseñadas en este proyecto se desarrollan en relación a los objetivos establecidos en el Boletín Oficial del Estado (BOE), según las tres áreas de la etapa de Educación Infantil: Conocimiento de sí mismo y autonomía personal, Conocimiento del entorno y Lenguajes: comunicación y representación. Sin embargo, dado el carácter del proyecto, destacan con una mayor preponderancia los objetivos y contenidos del área de Conocimiento del Entorno. Así, destacan fundamentalmente los objetivos que reflejan mejor las características propias de las Escape Rooms Educativas, el trabajo en equipo, la inclusión de la didáctica de la Historia en Educación Infantil, las relaciones sociales, el descubrimiento e interactuación con el entorno y el desarrollo del alumno a través de la experimentación como factores principales. 
El proyecto cuenta con un total de 7 sesiones. Las sesiones han sido desarrolladas de acuerdo tomando como punto de partida la vida de un ganadero trashumante. Así, el alumnado deberá adoptar los roles en la órbita de este oficio tradicional: mayorazgos (dueños del rebaño) rabadanes (pastor que tiene a cargo varios rebaños y pastores), yegüeros (encargado de la caballería) y pastores. Para ayudar al docente en el proceso de guía del proyecto, se le proporcionó un breve dossier, con la historia sobre la trashumancia, los orígenes de esta práctica, y datos relacionados con el desarrollo y las características propias del proceso, como el reparto de responsabilidades durante los viajes con el ganado, o el reparto del jornal.

Así, la propuesta didáctica que se muestra tiene como objetivo simular el camino que los pastores trashumantes deben hacer, desde el norte de la Península Ibérica hasta los pastos del sur, durante los meses de otoño e invierno. El propósito de estos largos viajes, desplazando al ganado con las pertenencias básicas, es que los rebaños puedan abastecerse de la suficiente comida para no perecer, en un clima más óptimo. En este caso la vía pecuaria que se les propone recorrer a los alumnos, es de Burgos a Cáceres, pasando por Palencia, Valladolid, Ávila y Salamanca. Cada una de las ciudades es correspondida con una sesión. Así, para poder viajar de una ciudad a otra, los alumnos deberán resolver con éxito cada una de las actividades que se proponen en las diferentes sesiones. Esto les permitirá pasar de una sesión a otra y así, avanzar en el mapa, de una ciudad a otra.

Durante el proceso de resolución de actividades, al finalizarlas, cada grupo recibirá del docente una pieza de un puzle. Esta pieza será la llave que les permite superar cada sesión y avanzar. Así cada grupo completará el puzle con la pieza que han recibido, lo que dará como resultado la silueta de la provincia a la que viajarán en la siguiente sesión.

Cada una de las sesiones está diseñada para llevarse a cabo en cuatro partes. La primera es la de exposición de la información de cada uno de los cuatro roles. En cada una de las sesiones, cada uno de los roles establecidos (mayorazgo, rabadán, yegüero y pastor), deberá realizar una breve investigación con ayuda de los adultos a su cargo, que posteriormente expondrán, para ello se ha diseñado una ficha en formato PDF con la que los adultos (padres, madres, abuelos) contarán en todo momento como guía, además de un listado en el que se relaciona a cada alumno con el apartado sobre el que deberá investigar y exponer. Los mayorazgos deberán informarse acerca de la ciudad en la que se encuentren en cada etapa / sesión. Para ello, la investigación estará pautada con un guion que simplifique el trabajo y permita a todos participar en el mismo grado. La información contenida en cada caso, incluye: el nombre de la ciudad que corresponda en cada caso, los habitantes de la misma, un ejemplo de un monumento o paisaje destacado de la provincia junto con una imagen que lo ejemplifique y, por último, el patrón de la ciudad y el momento en que se celebran las fiestas patronales.

Las fichas / guiones de los alumnos están diseñadas con el fin de establecer un primer contacto con la escritura, por lo que contarán con un patrón punteado para familiarizarse 
con las grafías mientras repasan el punteado. Así mismo, la información objeto de investigación no debe ser escrita necesariamente por al alumnado, que podrán contar con la ayuda de un adulto, sí es importante que se familiaricen con esta información para poder trasmitirla.

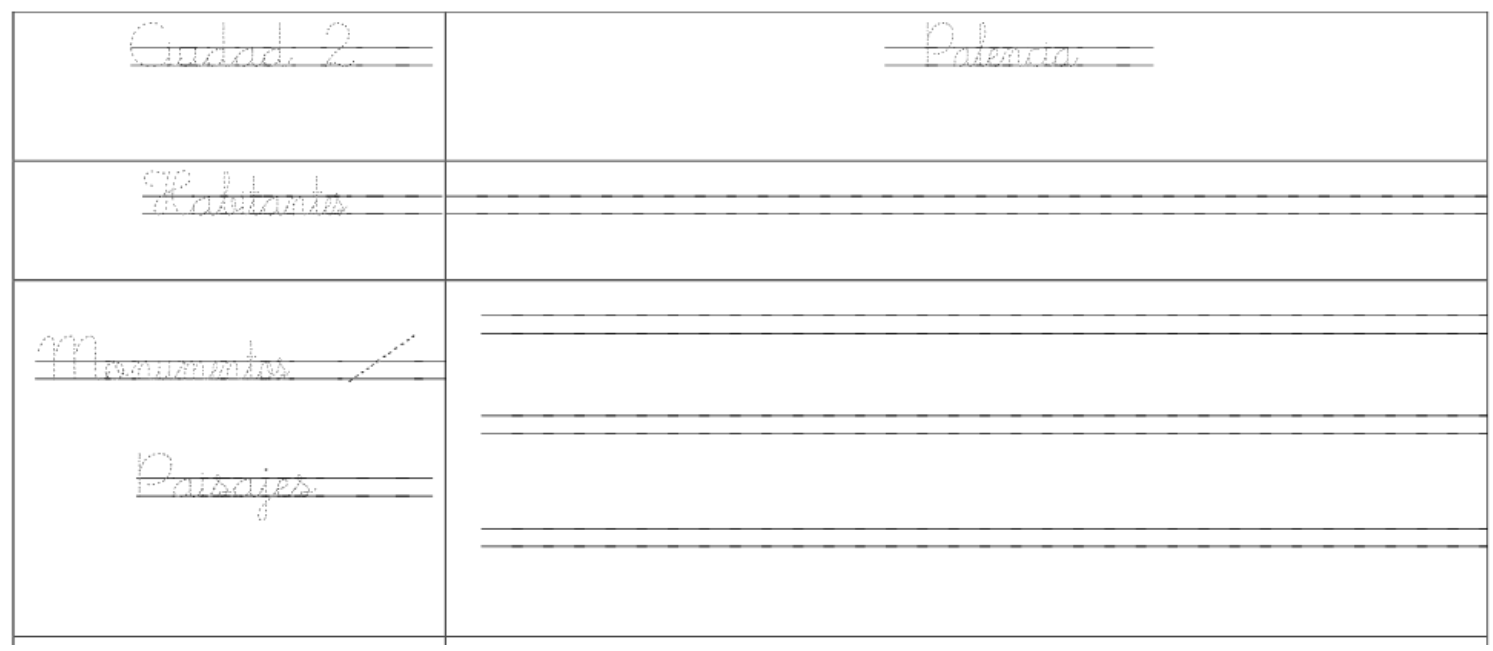

Figura 1. Fragmento de la ficha de las ciudades para el grupo de Mayorazgo. Creación propia

En el caso de los rabadanes la información que deberán investigar y posteriormente presentar a sus compañeros es acerca de recetas de cocina tradicionales de cada ciudad, preferentemente en relación con la trashumancia. Deberán ser recetas que requieran pocos ingredientes, propios de la región, que puedan ser cocinados de forma tradicional. Se trata de poner en conexión al alumnado con la alimentación propia de estas actividades, y que reflexionen acerca de su implicación en el pasado y en el presente. La dieta propia de este tipo de actividades se basaba en una alimentación a base de migas, la caza de algún conejo o el aprovechamiento de algún cordero que muriera en el camino, o algún animal salvaje cazado por los perros. Del mismo modo, los adultos a cargo, contarán con un documento en PDF en la que se informará acerca de la receta que deben elaborar y llevar al colegio. Se especificará tanto los ingredientes necesarios como una descripción del proceso de elaboración.

Para que los alumnos se familiaricen con la receta, deberán buscar imágenes de los ingredientes que se requieren en cada paso y pegarlos en la celda vacía que hay en cada uno de los pasos de la receta. Contarán con una tabla en la que se muestran todos los ingredientes, para ayudarles a identificarlos y buscarlos en cada caso. Además, se incluye información complementaria mediante un hipervínculo, que conduce a cada una de las recetas: sopas de ajo, migas, patatas a la importancia, patatas revolconas, hornazo y pestorejo extremeño. 


\section{PESTOREJO EXTREMEÑO}

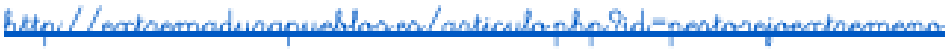

\begin{tabular}{|c|c|}
\hline Careta de cerdo troceada & Ajo \\
\hline Pimiento rojo & Cebolla \\
\hline Tomate & Perejil \\
\hline Pimentón & Vinaque \\
\hline Aceite & Sal \\
\hline
\end{tabular}

\begin{tabular}{|c|c|}
\hline PASO 1 & IMÁGENES INGREDIENTES \\
\hline $\begin{array}{l}\text { Echamos aceite en la santén y hacemos los } \\
\text { trocitos de la careta de cerdo. } \\
\text { Cuando esté tostada la echamos en la } \\
\text { cazuela (sin panerla al fueqo) }\end{array}$ & \\
\hline
\end{tabular}

\begin{tabular}{|l|l|}
\hline \multicolumn{1}{|c|}{ PASO 2} & IMÁGENES INGREDIENTES \\
\hline Troceamos la cebolla, tomates 4 pirmiento. & \\
En la sartén echamos aceite. & \\
Cuando esté caliente, echamos los trocitos do & \\
cebolla, tomates 4 pimiento. & \\
\hline
\end{tabular}

\begin{tabular}{|c|c|}
\hline$\overline{P A S O} 3$ & IMÁGENES INGREDIENTES \\
\hline 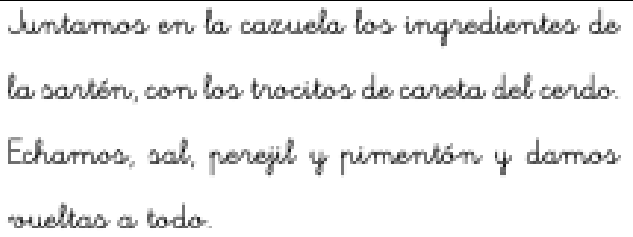 & \\
\hline
\end{tabular}

\begin{tabular}{|l|c|}
\hline PASO 4 & IMÁGENES INGREDIENTES \\
\hline Servimas. & \\
\hline
\end{tabular}

Figura 2. Ficha de receta para el grupo Rabadanes. Creación propia.

Los yegüeros trabajarán sobre dos temas diferentes: Tres de ellos investigarán acerca del otoño, el invierno y de la primavera (estaciones en las que se lleva a cabo la trashumancia). Indicarán su duración y características generales. Los otros tres yegüeros traba- 
jarán sobre la fauna típica de Palencia, Ávila y Cáceres, investigando acerca de qué animales pueden encontrarse en la zona (unos tres o cuatro ejemplos), del que elegirán uno para anotar información sobre su tamaño, su alimentación y su hábitat, que completarán con una imagen que facilite la identificación del mismo.

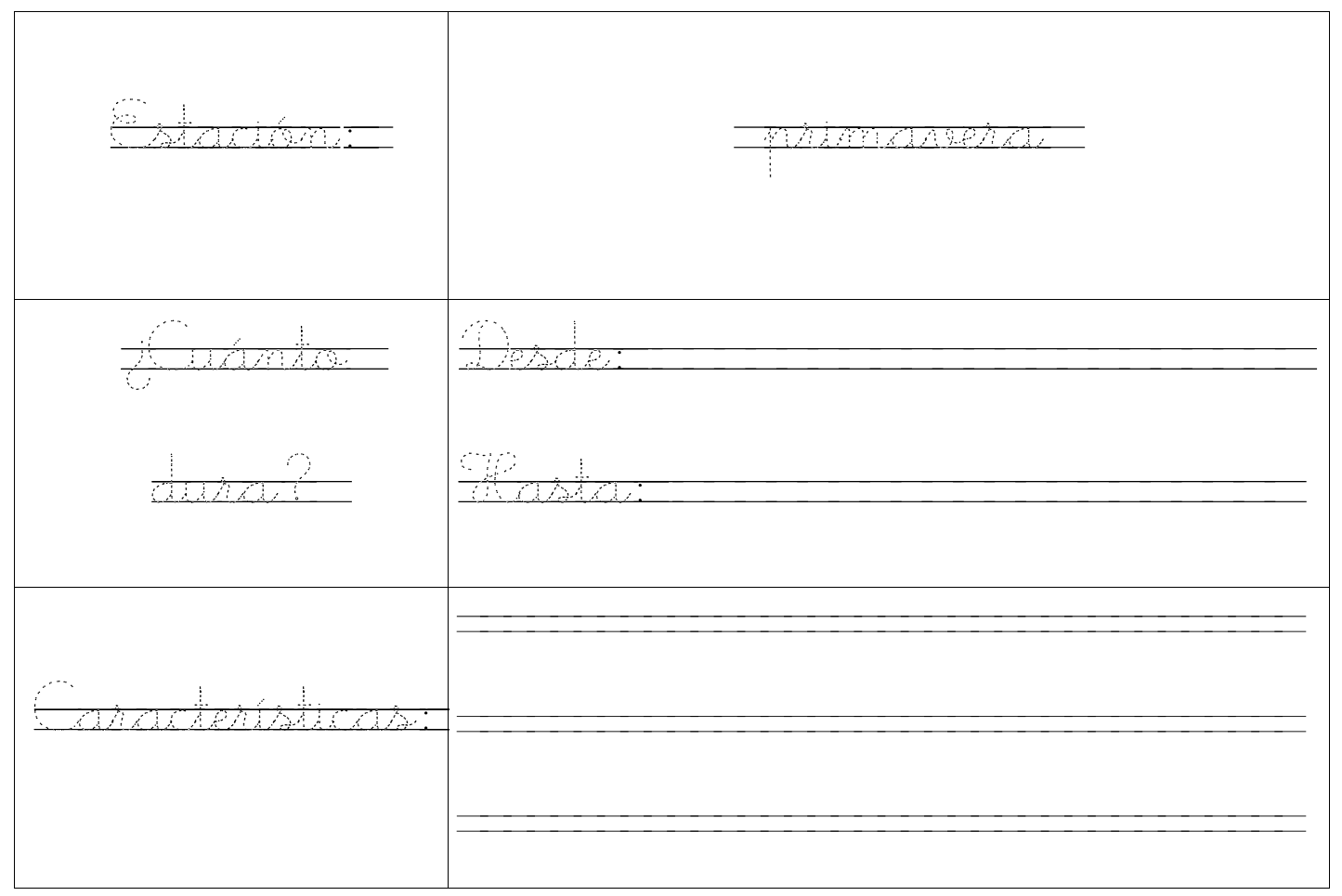

Figura 3. Ficha de estaciones para el grupo Yegüeros. Creación propia.

Por último, los pastores responderán a una serie de preguntas, que se les plantea en relación a la trashumancia: ¿Qué son las ovejas churras? ¿qué son las ovejas merinas?, ¿cuánto tiempo dura el viaje desde que parten hacia el sur hasta que vuelven?, ¿cuántos lechazos puede dar a luz una oveja churra? ¿en qué época?, ¿qué animales podrían atacar el rebaño durante el viaje?, ¿dónde se alojaban los pastores trashumantes?, y por último ¿en la actualidad hay vida trashumante? En la documentación (PDF) entregada a los pastores encontrarán las preguntas y espacios, tanto para las respuestas como para colocar imágenes que encuentren interesantes acerca de la información que manejan.

Una vez revisados todos estos materiales, se procede a llevar a cabo la primera sesión, llamada sesión 0. Así, se llevará a cabo la asignación de roles, mediante el reparto de tarjetas de cuatro colores distintos los cuales corresponden a cada uno de los roles, mayorazgo - azul, rabadán - rojo, yegüero - amarillo y pastores - verde.

Cada rol tiene una función que se mantiene a lo largo de toda la propuesta. Para ello se introducirá al alumnado en la temática con alguna anotación breve, de carácter conceptual. 


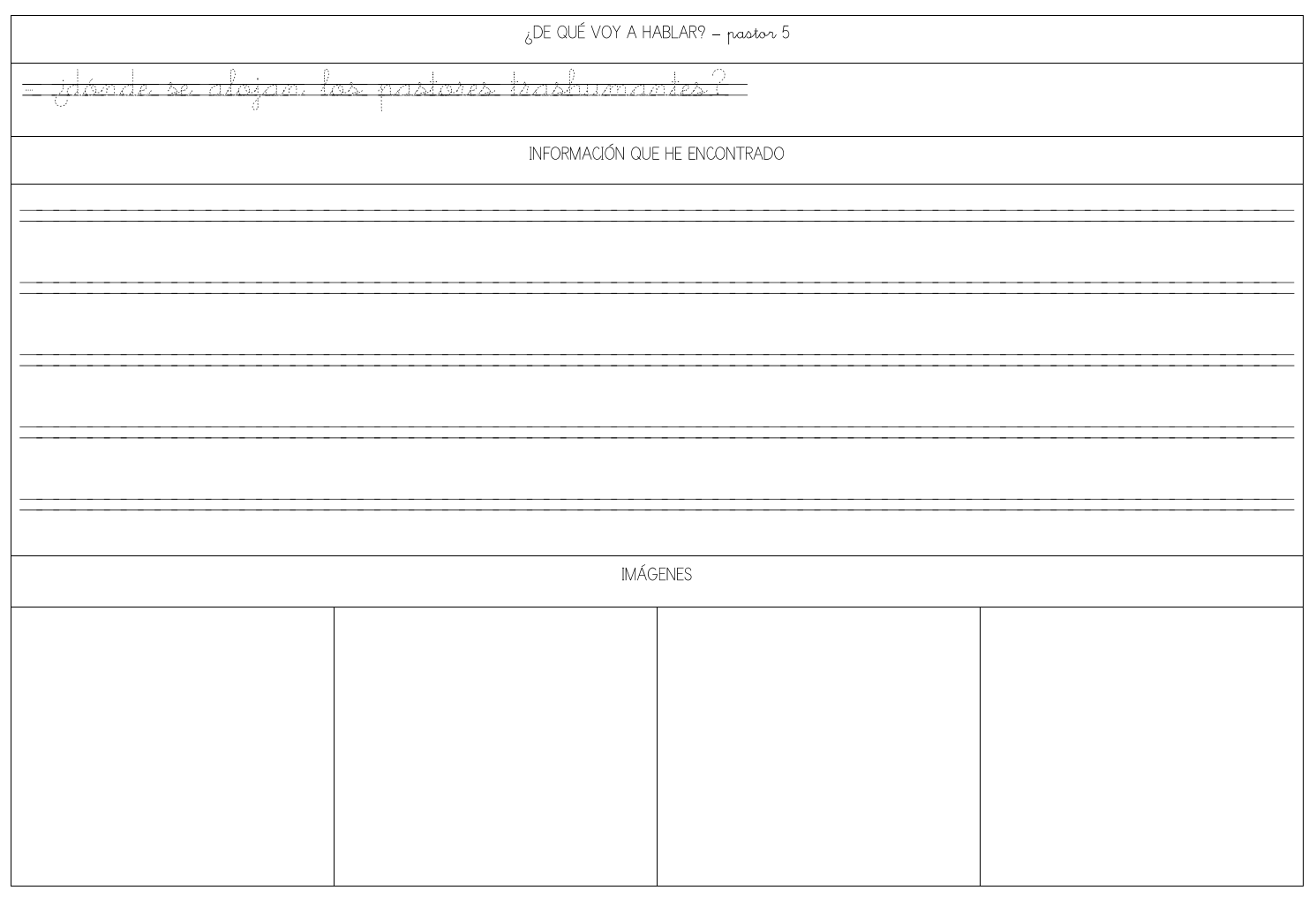

Figura 4. Ficha de cuestiones para el grupo Pastores. Creación propia.

Cada una de las sesiones consta de cuatro partes:

a) Exposición de la información relacionada con cada uno de los roles, que han investigado previamente con la ayuda de los adultos. Esta información deberá ser expuesta con claridad y escuchada con atención por el resto de participantes, ya que de ella extraerán la información que les ayudará a resolver las actividades que se les proponga en cada una de las sesiones.

b) Búsqueda de "pistas”. El alumnado deberá buscar por el aula "pistas" que les ayuden a llevar a cabo las actividades. Estas tendrán el color identificativo de su equipo, de manera que sea más fácil poder identificar qué deben buscar. Las azules son para el equipo de mayorazgo, las rojas para los rabadanes, las amarillas para los yegüeros y las verdes para los pastores. Durante diez minutos buscarán activamente las pistas en el aula y las dejarán en la mesa asignada a su equipo.

c) Realización de las actividades. Para ello, se ayudarán de las pistas que han encontrado. Cada grupo, realiza su actividad y una vez terminada se pone en común para propiciar un aprendizaje cooperativo.

d) La llave. Cada grupo contará con una parte de la silueta de una de las provincias trabajadas en el proyecto, donde "viajarán” en la siguiente sesión. Cada silueta funciona como una llave que les permitirá avanzar de una sesión a otra. 


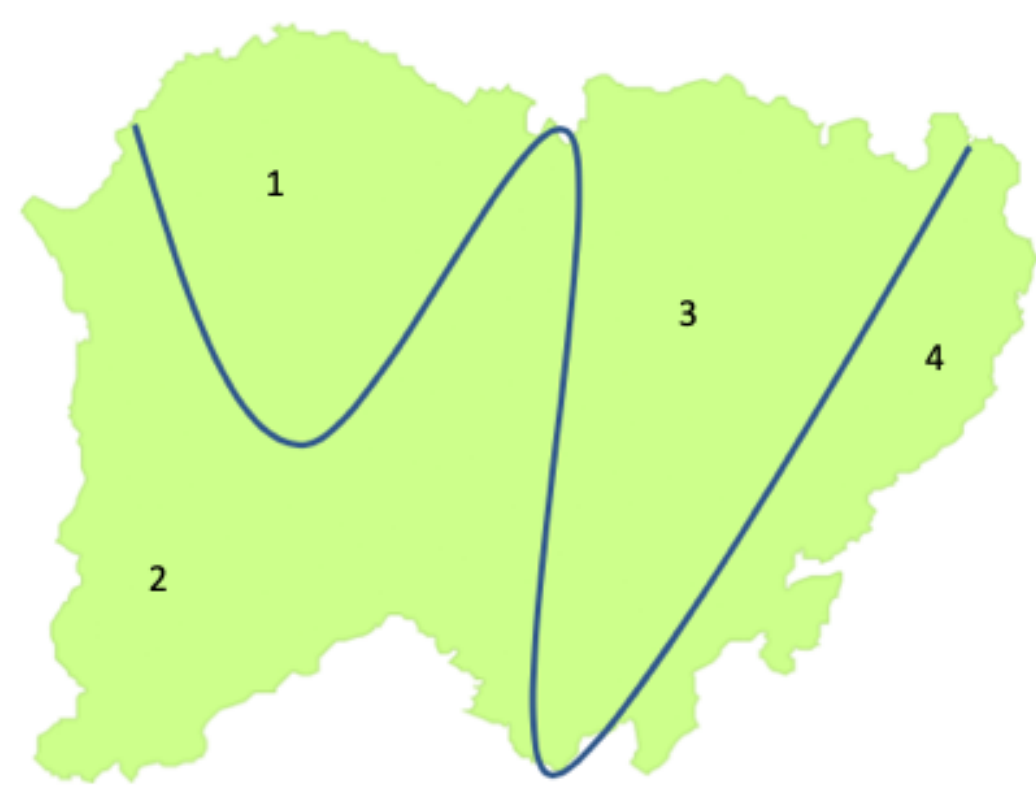

Figura 5. Mapa de la provincia de Salamanca dividido por piezas de puzle. Creación propia.

La última de las sesiones cuenta con una variación respecto a las anteriores, incluyendo algunos aspectos de la simulación en la Escape Room. Los alumnos que cumplen el rol de mayorazgos son los responsables de administrar y repartir el sueldo a los demás grupos, una vez hayan finalizado su viaje. En esta sesión, por tanto, los mayorazgos no deben buscar "pistas" sino repartir el "dinero" (simbólico), que han conseguido en el desarrollo de algunas de las actividades realizadas previamente. El grupo de los mayorazgos deberán recibir la mitad del dinero dado que son los dueños del rebaño. Para ello, se pedirá a los alumnos que repartan el dinero en dos partes iguales. Uno de los dos montones será para los dueños del rebaño (mayorazgos) el segundo montón, se dividirá a la vez en tres partes iguales, que deberán ser entregadas a los rabadanes, los yegüeros y los pastores.

\section{Intervención en el aula}

Se ha podido llevar a cabo esta Escape Room Educativa a un aula de Educación Infantil de 4 años, de manera adaptada a las necesidades curriculares del colegio, seleccionando del total de actividades, aquellas que se han considerado más completas en relación a los objetivos planteados.

Como medida inicial se explicó al alumnado el funcionamiento de una Escape Room, como una actividad en la que las puertas de la clase se cerraban (simulando una habitación sin salida), por lo que se mantendrán en el aula hasta que cada grupo consiga unas determinadas "llaves" que les permitan salir. Se les indicó que no podían ir al baño mientras durasen las actividades por lo que antes de realizarlas, se les dejó ir al servicio. 
Una vez que estaban ya todos en clase preparados se dividieron los grupos que fueron los mismos en el resto de actividades. Una vez que todos tenían claro a qué equipo pertenecían, se explicaban las actividades que iban a realizar. La idea era trabajar por rincones, es decir, de lunes a jueves se iban a hacer siempre las mismas 4 actividades, pero iban rotando los grupos. Esta actividad se llevó a cabo con las dos clases de $2^{\circ}$ de Educación Infantil al mismo tiempo. Dos de los rincones estaban en relación con un proyecto inicial y las otras dos con el proyecto de la Escape Room. Los cuatro rincones eran los siguientes:

1. Una oca sobre el cuento de "El grúfalo" que se les había leído previamente.

En esta oca, cada casilla contiene una pregunta sobre el cuento, para avanzar tenían que acertar las preguntas. Es una actividad grupal, todos contestaban a la pregunta, deciden la respuesta correcta de manera consensuada y todos participan.

2. Series de imágenes relacionadas con la primavera.

La primera serie es un árbol sin hojas, un árbol con pocas hojas y un árbol frondoso, que representa el paso de las estaciones.

La segunda serie es una cueva vacía, una cueva con un oso y un oso despertando, que representa la hibernación, concepto trabajado previamente.

3. Camino de huellas (actividad de la Escape Room inicial).

La diferencia es que las esponjas no tienen que buscarlas, se les entrega diciéndoles que son huellas de animales que salen en primavera en los bosques (ellos como proyecto en la escuela han construido un bosque en el pasillo principal).

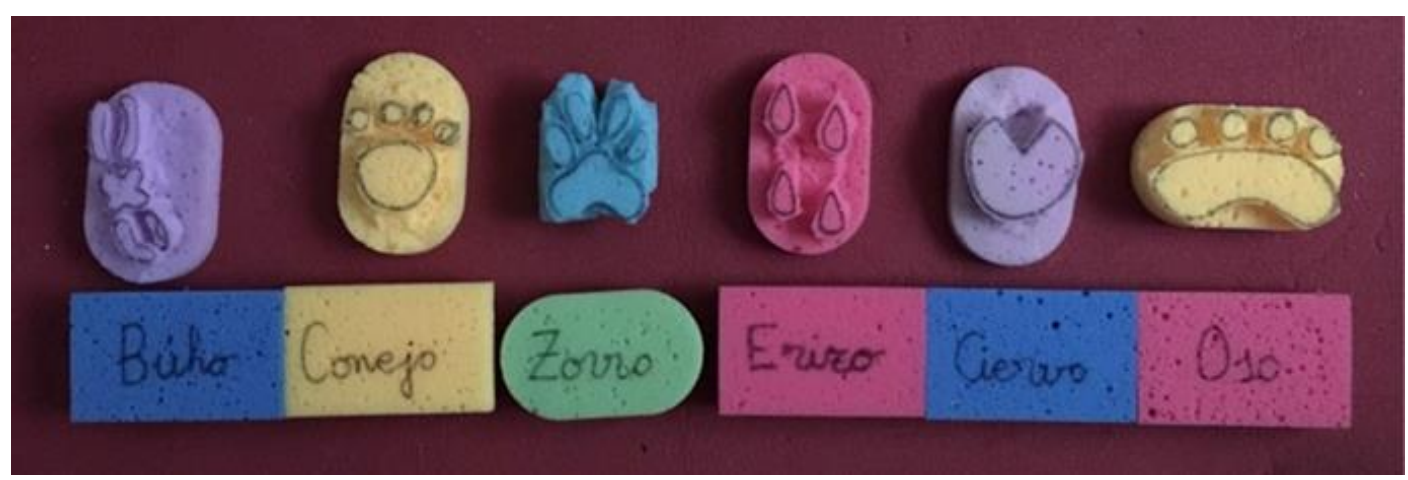

Figura 6. Esponjas con las huellas de los animales trabajados en la sesión 

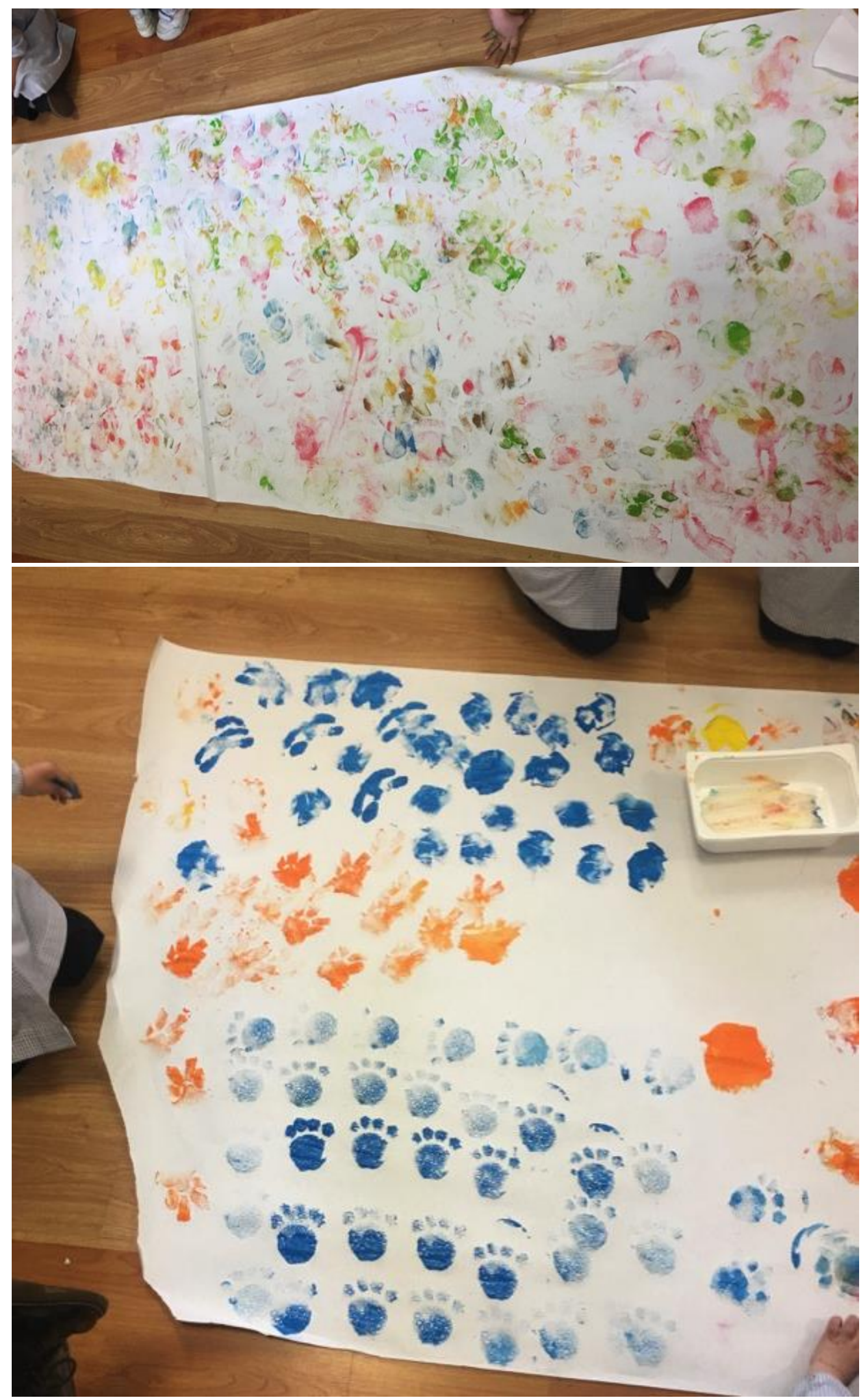

Figura 1. Camino de huellas confeccionado por los alumnos, con las esponjas de la figura 6. Autor: Noemí Sanz Yepes 
4. Flor con nuestras propias manos (también pertenece a la Escape Room inicial).

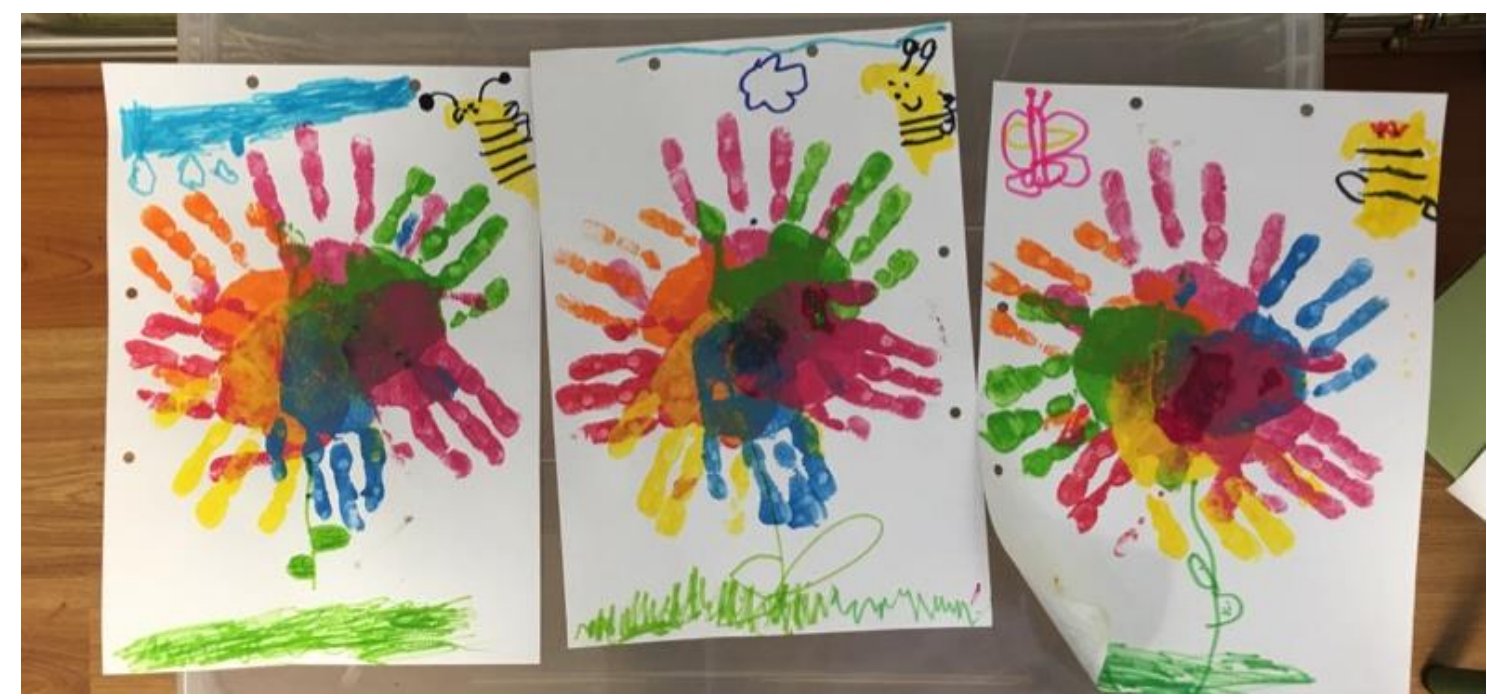

Figura 8. Flores confeccionadas por los alumnos. Autor: Noemí Sanz Yepes.

En la puerta de clase tenían las siluetas de las "llaves" que tenían que conseguir. Cada una de las imágenes que aparecen, forman parte de los procesos que dan nombre a los grupos y cada proceso está compuesto de 4 imágenes.

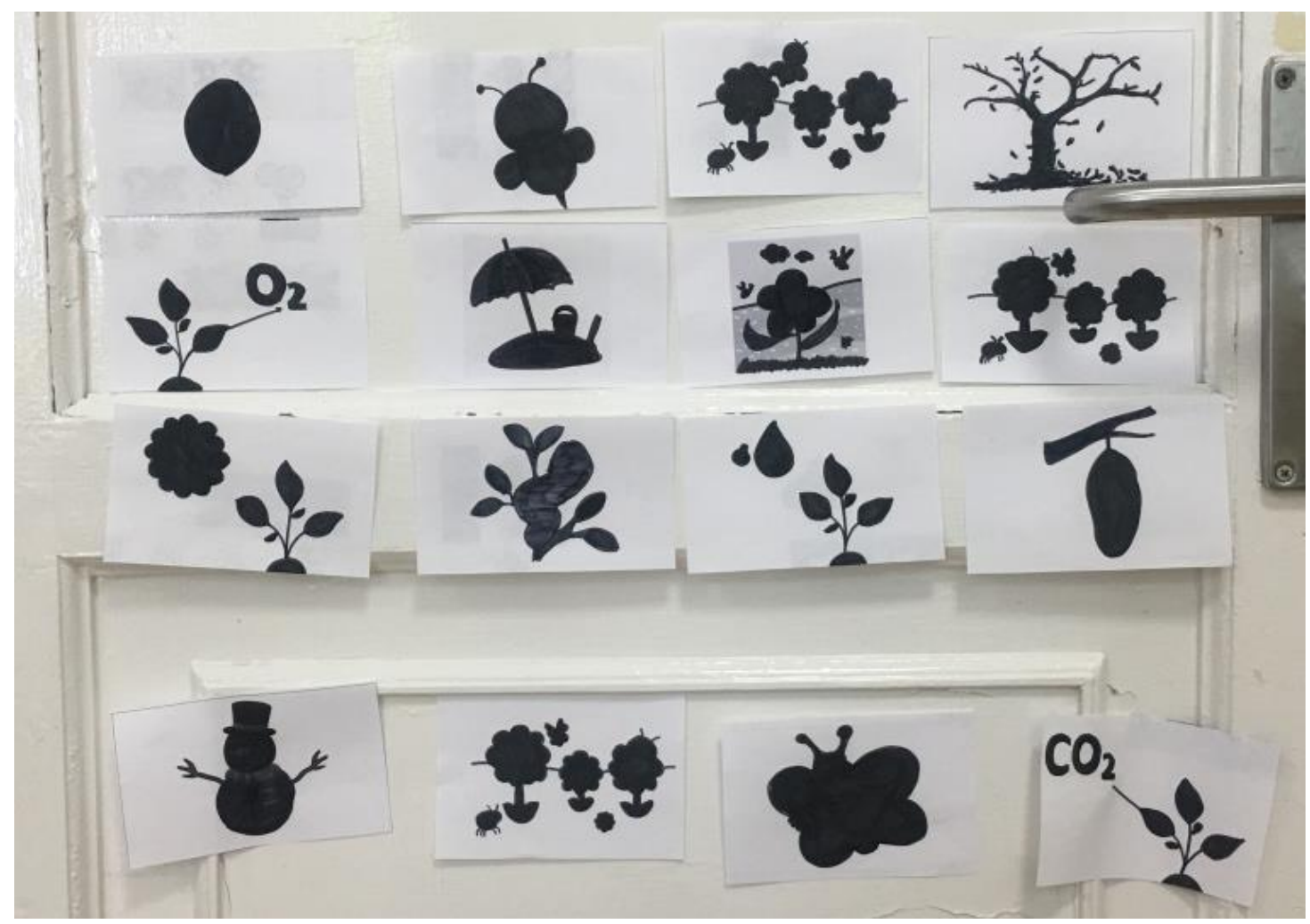

Figura 9. Siluetas de las imágenes correspondientes a cada equipo. Creación propia. 
Las siluetas están desordenadas, para dificultarles un poco la búsqueda, pero las imágenes que se les entregan cuando acaban las actividades, se entregan en orden. Cuando acababan las actividades se le entregaba a cada grupo la imagen que correspondiera y buscaban su silueta en la puerta. Una vez que conseguían encontrarla, la pegaban encima y si coincidía, podían salir de la habitación, lo que simbolizaba que habían encontrado la llave que había la habitación.

Esto lo hicieron de lunes a jueves hasta que consiguieron las 4 imágenes de cada proceso. Para finalizar, el viernes en asamblea, cada equipo expuso a sus compañeros en qué consistía el proceso asignado a su grupo, ayudándose de las imágenes que debían colocar en el orden adecuado.

\section{CONCLUSIONES}

A la hora de diseñar esta propuesta, una de las principales preguntas planteadas era: ¿Por qué no es hasta los primeros cursos de Educación Primaria cuando se empiezan a impartir clases especificas de Historia?

Teniendo en cuenta la aplicación en el aula de la propuesta y observando la aceptación de los estudiantes, extraemos las siguientes conclusiones. La novedad de la actividad supuso una alta aceptación, por lo que los alumnos iniciaron el trabajo con un alto grado de motivación. Esta circunstancia supone una ventaja a la hora de ser realizada ya que los alumnos lo perciben como algo nuevo e interesante y muestran una alta predisposición a experimentar y curiosidad por cómo se va a desarrollar. El alumnado se mostró participativo y eficaz a la hora de trabajar tanto en pequeños grupos, en grandes grupos y trabajo individual.

Con respecto a la aplicación de la Escape Room llevada a cabo en el aula de 4 años, La actividad fue propuesta como un reto, algunas de las actividades se llevaban a cabo de manera individual, pero el resultado grupal de las mismas era lo que iba a marcar si conseguían el objetivo, en este caso la llave, o no.

Positivamente se puede concluir que, es posible llevar a cabo una Escape Room en un aula de Educación Infantil. Los alumnos comprendieron la dinámica, respetando las normas que están implícitas en la aplicación de esta propuesta, casi ningún alumno pidió ir al servicio durante la realización de las actividades y cuando alguno lo pedía, los compañeros de equipo se encargaban normalmente de recordarle que no se podía. También se resuelve satisfactoriamente, lo que concierne al aprendizaje de conocimientos tanto conceptuales, como procedimentales y actitudinales a través de este recurso. Al finalizar la Escape Room todos los grupos eran capaces de explicar el proceso asignado a sus compañeros y colocaron las imágenes en el orden correcto. La oportunidad que ofrece de trabajo en equipo, es hacer partícipes a todos los alumnos del proceso y del resultado obtenido por su equipo y 
por el resto de equipos. De esta manera, se fomenta el aprendizaje significativo y el desarrollo del pensamiento crítico y deductivo de manera satisfactoria. El carácter lúdico de la actividad, así como la variedad de actividades, fomentaba el interés de los niños por realizarlas.

Teniendo en cuenta todo lo descrito sobre la propuesta llevada a cabo, se puede afirmar que no sólo es posible llevar a la práctica la propuesta planteada en un aula de Educación Infantil, sino que los resultados de su implementación son altamente satisfactorios. Los alumnos trabajaron importantes aspectos sociales como la aceptación y cumplimiento de las normas, el trabajo en equipo, la colaboración de todos los miembros con un objetivo común y la ayuda mutua. Por otro lado, aprendieron a reconocer los diferentes procesos asignados, ordenarlos secuencialmente y transmitir esta información al resto de los compañeros, que esta sea entendida y asimilada, logrando que el aprendizaje sea significativo.

Por lo tanto, podemos afirmar que, aplicar un modelo de enseñanza basado en la gamificación y adaptado a la edad de los alumnos, sus conocimientos y sus capacidades, no solo es factible, resultando además atractivo y diferente para el alumnado al que va dirigido, sino que resulta una buena herramienta didáctica para incluir la enseñanza aprendizaje de la historia en Educación Infantil.

\section{REFERENCIAS}

BLANCO, P. D., FERNÁNDEZ, C., MOLERO, B., ORTEGA, D., \& SÁNCHEZ, M. (2008). La formación en didáctica de las Ciencias Sociales del maestro de educación infantil. Una propuesta adaptada al Espacio Europeo de Educación Superior". Boletín Oficial del Estado. (11 de diciembre de 2018). Madrid, España.

CUENCA LÓPEZ, J. M. (s.f.). El currículo de Ciencias Sociales en la Enseñanza no Universitaria: del diseño al desarrollo. La enseñanza y el aprendizaje de las ciencias sociales en educación infantil. Huelva, España.

FERNÁNDEZ DÍAZ, Y., ORTIZ MARTÍNEZ, M., \& SERRA LARÍN, S. (enero de 2015). Importancia del juego para niños.

GODIN, B. (2012). Social Innovation: Utopias of Innovation from C.1830 to the present. Project on the Intellectual History of Innovation.

MARÍN, I., \& HIERRO, E. (s.f.). Gamificación. El poder del juego en la gestión empresarial y la conexión con los clientes.

MICHAVILLA, F. (2009). La innovación educativa. Oportunidades y barreras. Madrid, España. 
MIRALLES MARTÍNEZ, P., \& RIVERO GRACIA, P. (22 de marzo de 2012). Propuestas de innovación para la enseñanza de la historia en Educación Infantil. Murcia, España.

NICHOLSON, S. (2015). Peeking behind the locked door: A survey of escape room facilities.

RAMÍREZ MONTOYA, M. S., \& VALENZUELA GONZÁÑEZ, J. R. (2017). Innovación educativa. Investigación, formación, vinculación y visibilidad. Madrid, España.

SEBARROJA, J. C. (2002). El profesor y la innovación educativa. Madrid. 